\title{
Practice and Exploration on Constructing of Students' Innovative Laboratory Based on the Cooperation between Enterprises and Universities
}

\author{
W.-B. Zeng ${ }^{1}$, Jia Zhao ${ }^{2}$, Q.-Q.Wu ${ }^{1}$ \\ ${ }^{1)}$ School of Electrical and Information Engineering, Guangxi University of Science and Technology, LiuZhou, GuangXi, China \\ 2) School of Computer, Guangxi University of Science and Technology, LiuZhou, GuangXi, China
}

\begin{abstract}
Constructing of students' innovative laboratory based on cooperation between enterprises and universities is both a new philosophy of higher education and a new mode of cultivation of innovative ability. Through the practice of the cooperation between enterprises and Guangxi University of Science and Technology, this paper expounds the thinking, the goal and the main modes of constructing of students' innovative laboratory based on the co-construction. Moreover, the main content, the management as well as the incentives and activities of the laboratory are discussed thoroughly.
\end{abstract}

Keywords - cooperation between enterprises and universities, innovative talents, students' innovative laboratory, co-construction

\section{基于校企合作大学生创新实验室建设的探索与实践}

\author{
曾文波 $^{1}$ 赵嘉 $^{2}$ 吴其琦 $^{1}$ \\ 1) 广西科技大学电气与信息工程学院, 柳州, 广西, 中国 \\ 2) 广西科技大学计算机学院, 柳州, 广西, 中国
}

摘 要 校企合作共建大学生创新实验室, 既是一种新的学校开放办学的教育理念, 更是一种新的培养学生创新能力的模式。文 章通过广西科技大学与企业合作建设电气信息类大学生创新实验室的实践, 阐述了校企共建创新实验室的思路、建设目标及主要模式, 并对建设内容、管理模式、激励机制和实验室的活动内容体系，作了较深入地探讨。

关键词 校企合作, 创新人才, 创新实验室, 共建

\section{1. 引言}

面向企业培养技术应用型创新人才，是我国高等工程 教育的主要任务之一。基于创新实验室大学生创新能力培 养模式，近年来被中国各高校广泛采用，并取得了巨大的 成绩，积累了许多经验 [1]。广西科技大学从上世纪90年代 开始, 就成立了以培养电气信息类专业创新能力、实践动 手能力为主的电气信息创新实验室, 作为培养创新人才的 重要平台。电气创新实验室多年来吸引、鼓励了广大热爱 电气电子技术、喜欢动手制作大学生的积极参与, 为他们 开展课外科技活动创造了条件, 成为培养大学生真正从理 论到实践, 系统地掌握电子理论、电子设计、电子制作等 来, 广西科技大学积极与地方电气电子企业开展密切合作
知识提供了的阵地。

随着我国高等教育由 “精英教育” 转向 “大众教育”, 高校创新教育的内容、模式及面向发生了根本的改变。校 企合作办学, 已经从课内合作深化到了课外合作, 从普通 实验室的合作, 深化到 “创新实验室”、“创新基地” 的合 作。高校通过与企业合作, 共同建立创新实验室、创新基 地, 争取到企业在资金、设备方面的支持, 更容易实现由 传统的封闭式教学向产、学、研的共同发展, 培养的创新 人才也更容易与企业 “零距离”, 而企业也更容易在校企合 作的过程中, 发现符合企业发展需求的创新人才 [2]。校企 合作共建 “创新实验室”, 能使学校和企业 “共赢”。近年 共建创新实验室, 为大学生创新创业活动提供了保障。 


\section{2. 校企合作共建创新实验室的思路}

\section{1 创新实验室与普通专业实验室的区别}

普通的专业业实验室功能比较单一, 实验内容相对简 单, 主要服务于课内教学, 完成相应的教学任务, 其实验 内容及实验设备一般都固定不变。此外, 专业实验室服务 对象是全体修课的学生, 学生在学校安排好的时段到实验 室完成固定的实验内容, 完成实验报告, 教师根据学生在 实验室表现、实验报告的水平和实验考试来对学生教学考 核并给出考核成绩。

创新实验室是学生进行科技实践能力训练和进行创新 活动的专门场所, 属课外科技活动、科技创新实验场地, 其服务对象是学有余力、喜欢动手实践、渴望提高创新能 力的学生。不同学校有不同的创新实验室管理办法和建设 思路, 但其共同点是开设的实验项目由主要由学生自主选 择或指导老师选择, 创新实验室的设备更接近于生产、研 发的实际设备。此外, 创新实验室一般还具有学生技能培 训、学科竞赛培训等服务功能 [3]。

\section{2 校企共建创新实验室的一般目标}

企业和学校共办创新实验室, 是一种新的模式, 也是 一个发展方向, 共建创新实验室的目标应该包含以下两个 方面: (1) “人才培养” 原则: 创新实验室必须是以培养学 生创新能力为根本目标, 创新实验室的效果, 必须用能否 提高学生创新能力为标准去衡量, 这对于 “校企合作” 模 式的创新实验室也不例外, 人才培养是高校工作的最终目 标; (2) “共赢” 原则 : 市场经济体制下, 企业要在市场 竞争中立于不败之地, 必须有强大的技术创新能力, 而人 才是企业创新能力的保障, 企业可以通过与高校共建创新 实验室, 发现并选择适合自己的人才, 甚至是通过共建实 验室研发产品。此外, 高校在与企业的合作共建中, 也更 容易将高校的科技成果，更容易科研立项，同时也提高了 学生的就业与培养质量。“共建” 符合企业和学校的利益, “共赢” 必须是 “共建” 的主要目标。

\section{3 校企共建的模式}

\subsection{1 “企业配合” 模式}

这种模式中, 学校提供场地, 负责实验室的管理、实 验室制度的建设和实验内容的规划, 承担创新人才培养的 主要任务, 而企业重点在资金、设备等方面提供支持。在 这种模式中, 企业可以根据自身产品研发的需要, 给学校 提供相应的研究项目, 通过立项机制, 将企业的课题引入
到创新实验室, 同时, 企业也在创新人才选择方面得到实 惠。广西科技大学电气与信息工程学院, 近年来来与珠海 长陆工业控制有限公司等单位, 通过该合作方式, 取得了 良好的 “共赢” 效果。

\subsection{2 “校外创新基地” 模式}

主要由企业提供校外实验室场地, 学校和企业共同承 担实验室设备, 由学校负责实验室运行的方式。该模式重 点仍然是在人才培养, 但要求企业不仅参与研究和制定培 养目标、教学计划、教学内容和培养方式, 而且参与实施 与产业部门结合的那部分培养任务。

\subsection{3 “校企合办实体” 模式}

企业以设备、场地、技术、资金等多种形式与学校合 作办学, 组建实体公司或者实体培训机构, 承担该实体的 决策、计划、组织、协调等管理职能。企业以主人的身份 直接参与办学过程, 分享办学效益, 并通过参与办学实现 人才培养和自身人才选拔。

\section{3. 建设的内容及管理}

\section{1 场地及设备}

作为电气创新实验室, 创新实验室基础建设包括场地 和设备。以校内创新实验室为例, 其基本配置必须包括: (1) 电气电子开发工作平台。例如必要的示波器, 信号发 生器, 直流稳压电源, 数字万用表及工具箱, 以及各类开 发工具及必要的电气电子开发软件等。基础开发平台应该 满足学生进行常规电子制作的要求, 使电气创新实验室成 为学生进行课外创新科技活动和的基地。（2）展示区。展 示区设置的目的是营造实验室的学术氛围, 引导更多的学 生参与实践创新活动 $[4]$ 。广西科技大学电气创新室, 其展 示区的内容主要是介绍实验室的建设情况和所取得的成 绩, 主要设备有计算机、投影机, 作品展示柜等, 作品展 示柜展示的是历年来学生在创新实验室制作的优秀作品及 历届参加国内外重要学科竞赛获奖作品。

\section{2 制度保障体系}

实施校企合作共建创新实验室, 学校与企业必须深度 合作, 建立起能够实现校企共赢的制度保障体系。这些保 障学校与企业利益的制度必须体现以下内容: (1) 企业项 目优先原则。优先让合作企业提出的研究项目入驻实验室, 并在学生的配置上给予倾斜; (2) 成果共享原则。即合作 共建创新实验室的的研究成果由学校和企业共同拥有, 这 
些成果既包括学生的创新研究成果, 产生的专利, 也包括 学生在参加各类学科竞赛获奖后的对外宣传; (3) 经费保 障。合作双方必须签订相关协议, 明确各自在实验室的资 金、设备、管理上的投入; (4) 组织管理制度。学校必须 有相应的制度、措施保障, 用于激励广大学生的参与, 例 如, 建立必要的创新学分, 鼓励学生参与到实验室的科技 活动。

\section{3 运作机制}

\subsection{1 开放性运作原则}

创新实验室需要给学生营造一个宽松自由的环境, 给 学生的创造性提供广阔的空间, 校企共建的创新实验室也 必须遵循这一原则。实验室可以实行主要由专任教师监督、 学生自行管理的方式进行, 日常管理可由创新实验室学生 管理团队负责。共建的企业可不必具体参与日常的管理过 程。此外, 创新实验室可在时间和内容上同时开放, 即学 生可以自主选择研究的内容, 也可选择教师、企业提供的 创新课题, 真正体现创新实验室以人为本、重在人才培养 的核心内涵。

\subsection{2 激励原则}

与普通的创新实验室一样, 基于校企合作的创新实验 室, 必须有适合自身发展的激励机制。例如: 学校政策的 支持, 创新学分的获得等等。在实际的运作过程中, 企业 还可根据企业自身的情况, 根据学生的成绩, 给予必要的 奖励, 或优先录用在实验室创新活动成绩显著的学生。此 外, 企业还可以在验室开展由企业出题, 旨在解决企业技 术攻关难题的创新比赛, 提供一定数额的奖金, 激励指导 教师、有实力的学生共同参与。

\subsection{3 汇报机制}

企业作为创新实验室的合作者, 在实际运作过程中, 可能不直接参与具体的管理和监督, 但作为学校一方, 有 责任也有义务, 定期向合作企业汇报实验室的运作情况及 相关成果, 汇报机制必须写进学校与企业的合作共建协议。 3.4 活动体系

\subsection{1 科技创新活动培训}

技术培训是创新实验室的主要任务之一, 对于电气创 新实验室, 这些活动可以是在新加入创新活动团队的学生 中举办各种创新活动讲座, 可以是教学生对常用电子器件 识别、检测、基础项目设计制作等基础培训, 也可以带学 生到合作企业参观, 让学生了解生产一线的情况。培训内
容可多种多样, 培训员可以是学生团队的负责人, 可以是 老师, 也可以由企业技术人员来承担。

\subsection{2 学科竞赛的组织和集训}

参加学科竞赛是锻炼学生创新能力、团结协作精神和 科学精神的重要手段。电气信息类的学科竞赛较多, 重要 的有全国大学生电子设计竞赛、全国 “挑战者” 杯创新竞 赛等等, 创新实验室必须是这类学科竞赛的基层组织者和 培训基地, 而企业可在学生参与这些活动的过程中, 发现 并支持符合企业利益的创新人才。

\subsection{3 企业项目和企业举办竞赛}

企业可通过各种方式将企业的利益需求, 通过共建创 新实验室, 在培养学生创新能力的同时获得。例如, 企业 可将技术上的一些难题, 通过简化分解为一些基础性的题 目, 作为创新实验室的项目给学生做, 或者举办企业出题 的学科竞赛。实践表明, 尽管没有实际研发经验的学生不 能完成企业的实际攻关项目, 但企业往往能通过学生对化 简后的题目研究, 得到很多技术上有启示的思路, 获得意想 不到的效果。

\section{4. 结束语}

基于 “校企合作” 模式大学生创新实验室的建设, 体 现了以学生为本的思想, 注重 “共赢”。实践证明, 该模式 能有效地将大学的教学管理融进企业的先进管理模式, 能 有效地将教育思想与实践环境融入企业文化, 使学校创新 教学的内容不断得到更新和充实, 使学生的培养与社会的 需求更加接近。同时, 企业也能在校企合作中真正得到了 实惠。

\section{参考文献(References)}

[1] L. Guoqin, "On Construction Practice of Electronics Innovation Base," RESEARCH AND EXPLORATION IN LABORATORY, vol. 28, no. 11, pp. 10-12, 2009.

[2] ZHANG Li-ying, "My Opinion of Deepening School-Enterprise Cooperation," Journal of Heilongjiang College of Education, vol. 29, no. 10, pp. 31-32, 2010.

[3] ZHOU Xiao-lan, CHEN Yin-shan, ZHANG Yan-ding "Construction and Management of Innovation Lab for College Students," Journal of Fujian Normal University (Natural Science Edition), vol. 27, no. 3, pp. 56-58, 2011.

[4] HE Xiao-yang, ZHU Li-quan, ZHU Ya-ping, YU Zhi "Innovating the Management Model and Operational Routine for Laboratory," RESEARCH AND EXPLORATION IN LABORATORY, vol. 25, no. 1, pp. 113-115, 2006. 